\title{
Fibromiyalji Sendromu Hastalarının İşlevsellik, Yetiyitimi ve Sağlığın Uluslararası Sınıflandırılması (ICF) Kapsamında Değerlendirilmesi: Pilot Çalışma
}

\author{
Bahar Dernek®
}

İstanbul Fizik Tedavi Rehabilitasyon Eğitim ve Araştırma Hastanesi, Istanbul, Türkiye

Bahar Dernek, Doç. Dr.

Illetişim:

Doç. Dr. Bahar Dernek

Sağılk Bilimleri Üniversitesi, İstanbul Fizik Tedavi ve Rehabilitasyon SUAM, Istanbul, Türkiye

Tel: +905397170944

E-Posta: bahardernek@gmail.com

Gönderilme Tarihi : 31 Temmuz 2018

Revizyon Tarihi : 16 Ekim 2018

Kabul Tarihi : 18 Ekim 2018

\section{ÖZET}

Amaç: Bu çalışmanın amacı, kronik yaygın ağı (KYA) için geliştirilmiş olan Işlevsellik, Yetiyitimi ve Sağığın Uluslararası Sınıflandırıması (ICF) çekirdek dizisinin fibromiyalji sendromu (FMS) hastalarındaki sağlık sorunlarının etkinlikler ve katılım ile çevresel faktörler bileşeninde değerlendirilmesidir.

Hastalar ve Yöntemler: Bu çalışma prospektif, kesitsel bir pilot çalışma olarak planlandı ve 2017 Haziran-2018 Mart ayları arasında yürütüldü. Çalışmada KYA için Kısa ICF Çekirdek Dizisi ICF kullanııld. Bu ICF çekirdek dizisinde yer alan 24 kategori, 254 FMS hastası üzerinde değerlendirildi. Vücut işlevleri, etkinlikler ve katılım alanlarındaki kategoriler 0-4 arası puanlama ile değerlendirildi.

Bulgular: Hastaların \%97,6'sı kadın iken ( $n=248), \% 2,4^{\prime}$ ï erkekti $(n=6)$. Vücut işlevlerinde yapılan değerlendirmeye göre özellikle enerji, uyku, psikomotor fonksiyon, emosyonel durum, düşünce içeriği, ağn, egzersiz tolerans, ve kas kuvveti kategorilerinde orta veya ciddi düzeyde bozukluk tespit edildi. Etkinlikler ve katılım alanında yapılan değerlendirmeye göre ise, problem çözme, günlük yaşam aktivitelerin yerine getirme, stresle baş etme, cisimleri kaldırma-taşıma, yürüme, ev işi yapma, aile ilişkileri, yakın ilişkiler, işe başlama-devam ettirme, boş zamanlarııı değerlendirme kategorilerinde orta veya ciddi düzeyde sorun tespit edildi. Çevresel faktörler alanı incelendiğinde ilaç kullanımı, aile ilişkileri, sağık profesyonellerinin tutumu, yakın aile ilişkileri, ve sosyal sistemlerin ve politikalarının genel olarak orta düzeyde kolaylaştırııı olduğu tespit edilmiştir.

Sonuç: FMS, sadece hasta olan bireyi değil, bireyin yaşadığı alanda bireyle etkileşim halinde olan diğer toplumsal bireyleri ve grupları da etkileyen ve geniş çaplı sistemik etkilerin ortaya çıkmasına neden olan kronik bir hastalıktır. ICF sistemi ile FMS gibi hastalıklarda, sadece hastalı̆ı̆ı etkileri değil, hastalı̆ı̆ direk veya dolaylı olarak oluşturduğu çevresel etkiler de ayrnntılı olarak incelenebilir.

Anahtar sözcïkler: Fibromiyalji, kronik yaygın ağrı, ICF, işlevsellik, yetiyitimi

EVALUATION OF FIBROMYALGIA SYNDROME PATIENTS WITH INTERNATIONAL CLASSIFICATION OF FUNCTIONING, DISABILITY AND HEALTH (ICF): A PILOT STUDY

ABSTRACT

Objectives: The objective of this study was the evaluation of the International Classification of Functioning, Disability and Health (ICF) core set which was developed for chronic widespread pain (CWP) in patients with fibromyalgia syndrome (FMS) in terms of activities and participation, and environmental factors.

Patients and Methods: This study was designed as a prospective, cross-sectional pilot study and conducted between June 2017 and March 2018. A brief ICF core set for CWP was applied to patients. A total of 24 categories of the brief ICF core were applied to 254 FMS patients. Categories of body functions and activities and participation were scored between 0 and 4 .

Results: Among enrolled patients, $96.7 \%$ ( $n=248)$ were females and $2.4 \%(n=6)$ were males. Among body function evaluations, mild and severe disturbances were observed in energy, sleep, psychomotor function, emotional function, content of thought, pain, exercise tolerance, and muscle power categories. In activities and participation, mild and severe disturbances were determined in problem-solving, carrying out a daily routine, handling stress, lifting and carrying objects, doing housework, family relationships, intimate relationships, acquiring and keeping a job, recreation and leisure categories. Among environmental factors, individual attitudes of health professionals, family relationships, and social services, systems and policies were considered moderately facilitating factors.

Conclusion: FMS is a chronic disease that affects not only the patient but also the individuals or groups who are in contact with the patient. With the use of ICF, environmental effects caused directly or indirectly by the disease may be evaluated in chronic diseases such as FMS.

Keywords: Fibromyalgia, chronic widespread pain, ICF, functioning, disability 
laç tedavileri ve rehabilitasyon programları hastaların fonksiyonelliğini ve sağlık durumlarını mümkün olan en iyi hale getirebilmek için kullanılır. Dolayısıyla hastaların ya da hastalıkların hastalar üzerindeki etkilerini sınıflandırma ve ölçüm yöntemleri klinik pratikte olduğu kadar bilimsel eğitim ve çalışmalarda da önemli yer tutar (1). Bu bağlamda geliştirilen İşlevsellik, Yetiyitimi ve Sağlığın Uluslararası Sınıflandırılması (International Classification of Functioning, Disability and Health [ICF]) (2) araştırmacılar, klinisyenler ve klinik eğitimcilerin ilgi alanında yer almaktadır (1).

ICF'nin işlevsellik ve yetiyitimi modeli biyopsikososyal bir modeldir ve sağlığı, biyolojik, kişisel ve sosyal yönleri de dâhil olmak üzere, birçok açıdan ele alır. Şekil 1 ve 2'de de görüldüğü üzere bireyi işlevselliği veya yetiyitimi durumu "sağlık durumu" (hastalıklar, bozukluklar, yaralanmalar ve travmalar, vs.) ile bağlamsal etmenler ("çevresel etmenler" ve "kişisel etmenler") arasındaki ilişkiyi yansıtır (3). ıCF Sisteminde vücut işlevleri ve etkinlikler ve katılım alanlarındaki katego riler 0-4 arası puanlama ile değerlendirilir (sorun yok/hafif sorun/orta sorun/ciddi sorun/tam sorun) (Tablo 1 ve 2).

ICF farklı alanlarda 1400'den fazla kategori içermesi dolayısıyla mükemmele yakın bir değerlendirme sistemi olması yanında klinik pratikte veya poliklinik şartlarda kullanıması açısından pratik değildir. Bu sorunu aşmak adına her hastalık için ayrı ICF kategorileri içeren ICF çekirdek dizileri oluşturulmuştur (4). ICF çekirdek dizileri de kısa ve kapsamlı olmak üzere iki farklı şekilde belirlenmiştir. Kısa ICF çekirdek dizisinin klinik çalışmalarda kullanılması önerilirken, kapsamlı ICF çekirdek dizisinin daha çok multidisipliner değerlendirmeler için kullanılması önerilmektedir (1-5).

ICF çekirdek dizilerinin geliştirdiği sık rastlanan sağlık sorunlarından biri de kronik yaygın ağrı (KYA)'dır (4). KYA, vücudun çeşitli bölgelerinde yaygın kas ağrısı ve hassasiyet ile karakterize ve sık rastlanılan bir kas iskelet sistemi hastalığıdır. Fibromiyalji Sendromu (FMS) da KYA'nın en ciddi klinik durumlarından biridir.

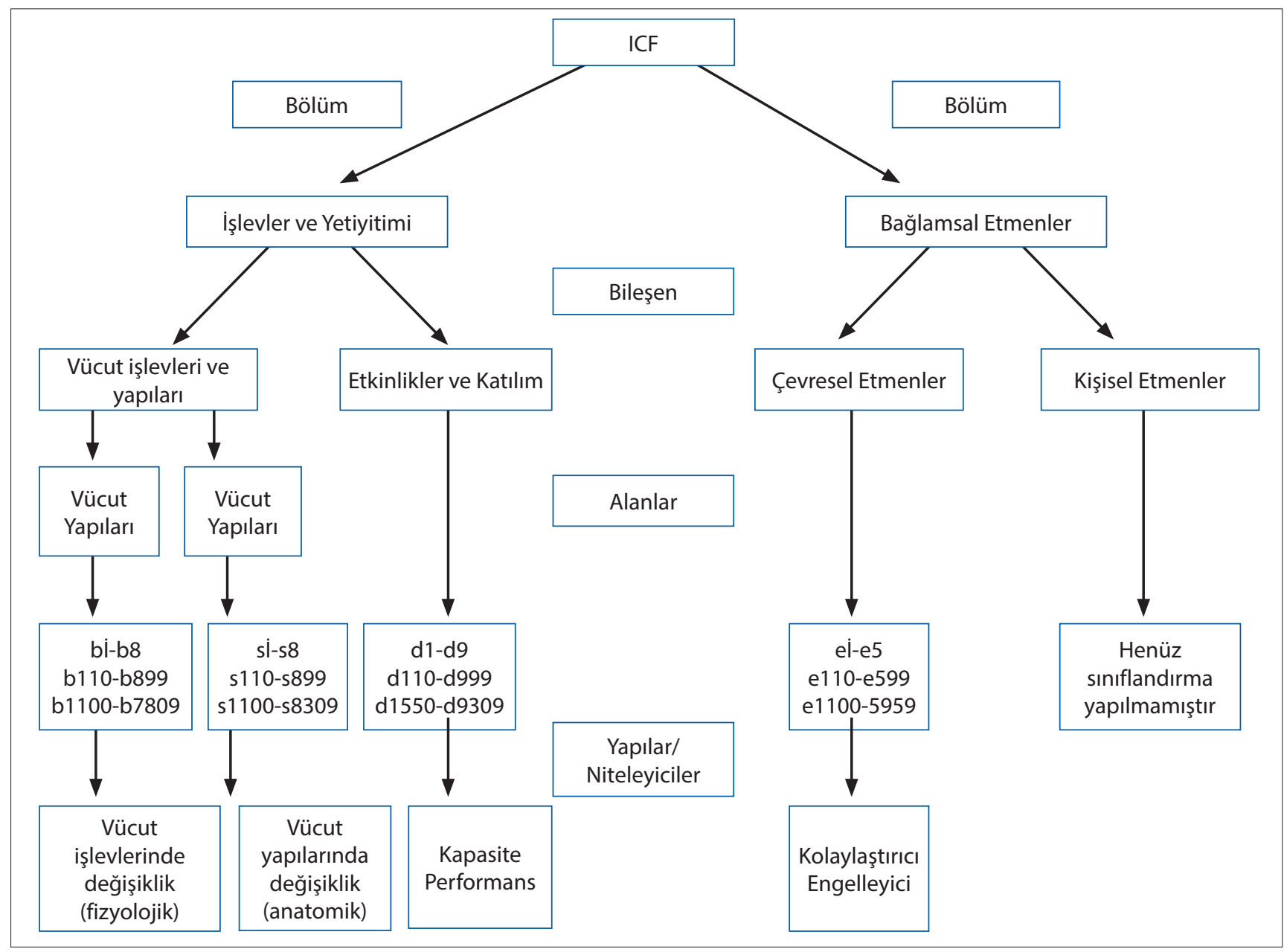

Şekil 1. ICF'nin genel hiyerarşik yapısı ve niteleyiciler ile olan ilişkisi 


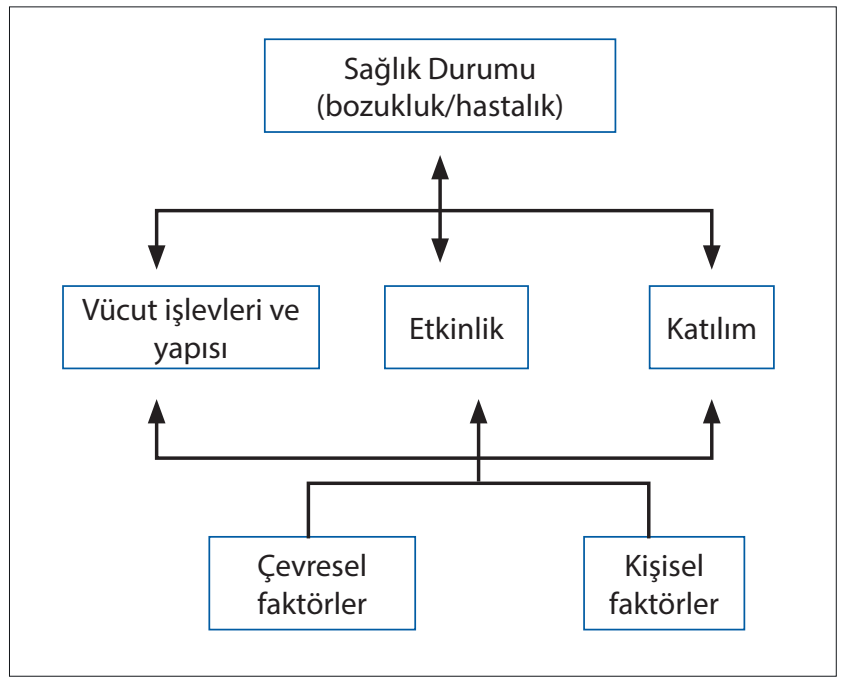

Şekil 2. ICF bileşenleri arasındaki etkileşim

Tablo 1. ICF genel niteleyici ve geniş yüzdelik dilimlerin ilişkisi

\begin{tabular}{lll}
$\begin{array}{l}\text { Problem } \\
\text { Düzeyi }\end{array}$ & Açıklama & Yüzdelik Dilim \\
\hline 0 & Problem yok (hiç/ihmal edilebilir) & $\% 0-4$ \\
1 & Hafif düzeyde problem (az, düşük) & $\% 5-24$ \\
2 & Orta düzeyde problem (orta, az çok) & $\% 25-49$ \\
3 & Ciddi düzeyde problem (aşıı) & $\% 50-95$ \\
4 & Tam problem (tamamen) & $\% 96-100$ \\
8 & Belirtilmemiş & \\
9 & Uygulanamaz &
\end{tabular}

FMS tanısı için en sık kullanılan tanı kriterleri 2016 yılında Amerikan Romatoloji Birliği [American College of Rheumatology (ACR)] tarafından oluşturulan kriterlerdir (6) (Tablo 3).

FMS'de ağrıya ek olarak hastalarda yorgunluk, uyku sorunları, psikolojik problemler ve başka sistemik birçok semptom olabilmektedir (7). Genel olarak toplumun \%0,5 ile \%4'ünün FMS'den dolayı çeşitli semptomlar taşıdığı bilinmektedir (8). Çalışma, günlük yaşam aktivitelerini yerine getirme ve fonksiyonel durumda çeşitli sorunlar olması hastaların sağlığını ve dolayısıyla yaşam koşullarını çeşitli ölçülerde zorlayıcı olabilmektedir (9-11).

Fonksiyonel durum hastaların yaşam deneyimlerinin temelini gösterir ve yine hastaların sadece sağlık durumları değil, çevresel faktörler ile kişisel karakterleri arasındaki etkileşimi ifade eder (9-11).

FMS'nin çok yönlü bileşenli bir hastalık olması dolayısıyla standart ölçüm yöntemleri ile hastalığın oluşturduğu etkilerin ayrıntılı olarak tespit edilmesi ve dolayısıyla terapötik yaklaşımların etkinliğinin değerlendirilmesini zorlaştırmaktadır (4). Bu zorluk, "Outcome Measures in Rheumatoid Arthritis Clinical Trials (OMERACT)" gibi çeşitli çalışmalarda gündeme gelmektedir. Bu tarz atölye

Tablo 2. ICF bileşenleri ve niteleyiciler

\begin{tabular}{|c|c|c|c|}
\hline Bileşen & $\begin{array}{c}\text { Birinci } \\
\text { Niteleyici }\end{array}$ & $\begin{array}{c}\text { Ikinci } \\
\text { Niteleyici }\end{array}$ & $\begin{array}{l}\text { Üçüncü } \\
\text { Niteleyici }\end{array}$ \\
\hline $\begin{array}{l}\text { Vücut } \\
\text { işlevleri (b) }\end{array}$ & $\begin{array}{l}\text { İşlev bozukluğunun şiddetini belirtir: } \\
0 \text { problem yok } \\
1 \text { hafif düzeyde problem } \\
2 \text { orta düzeyde problem } \\
3 \text { ciddi düzeyde problem } \\
4 \text { tam problem } \\
8 \text { belirtilmemiş } \\
9 \text { uygulanamaz }\end{array}$ & Yok & Yok \\
\hline $\begin{array}{l}\text { Vücut } \\
\text { apıları (s) }\end{array}$ & $\begin{array}{l}\text { İşlev bozukluğunun şiddetini belirtir: } \\
0 \text { problem yok } \\
1 \text { hafif düzeyde problem } \\
2 \text { orta düzeyde problem } \\
3 \text { ciddi düzeyde problem } \\
4 \text { tam problem }\end{array}$ & $\begin{array}{l}\text { İlgili vücut yapısındaki değişimin } \\
\text { özelliğini belirtir: } \\
0 \text { yapıda değişiklik yok } \\
1 \text { tümden yok } \\
2 \text { kısmen yok } \\
3 \text { ek bölüm } \\
4 \text { tipik olmayan boyutlar } \\
5 \text { devamsızlık } \\
6 \text { deviasyon } \\
7 \text { yapıdaki niteliksel değişim } \\
8 \text { belirtilmemiş } \\
9 \text { uygulanamaz }\end{array}$ & $\begin{array}{l}\text { İlgili vücut yapısındaki değişimin } \\
\text { yönünü belirtir: } \\
0>1 \text { bölgede } \\
1 \text { sağ } \\
2 \text { sol } \\
3 \text { her iki taraf } \\
4 \text { head on } \\
5 \text { arka } \\
6 \text { proksimal } \\
7 \text { distal } \\
8 \text { belirtilmemiş } \\
9 \text { uygulanamaz }\end{array}$ \\
\hline $\begin{array}{l}\text { Etkinlikler ve } \\
\text { katılım (d) }\end{array}$ & $\begin{array}{l}\text { Performans } \\
\text { Kişinin mevcut çevresine ait problemler }\end{array}$ & $\begin{array}{c}\text { Kapasite } \\
\text { Yardım olmaksızın sınırılık }\end{array}$ & Yok \\
\hline $\begin{array}{l}\text { Çevresel } \\
\text { etmenler (e) }\end{array}$ & $\begin{array}{l}\text { Negatif ve pozitif ölçekli genel niteleyici, } \\
\text { engeller ve kolaylaştırıcıların yaygınlığını belirtir }\end{array}$ & Yok & Yok \\
\hline
\end{tabular}




\section{Tablo 3. Fibromiyalji tanı kriterleri}

\section{Kriterler}

1. Yaygın ağrı indeksi 7 veya üzerinde ve semptom șiddeti skalası 5 veya üzerinde olan hastalar ya da yaygın ağrı indeksi 4-6 arasında ve semptom şiddeti skalası 9 veya üzerinde olması

2. Jeneralize ağrının bulunması (çene, göğüs ve abdomen haricinde belirlenen 5 bölgeden en az 4'ünde ağrı)

3. Semptomların en az 3 aydır aynı düzeyde olması

4. Diğer bir klinik tanının varığı FMS tanısını dışlamaz

\section{Tespit Etme}

1. Yaygın ağrı indeksi: Son hafta içerisinde ağrılı vücut bölgelerinin sayıs tespit edilir (skor $0-19$ aralığında)

Omuz kuşağı, sol-sağ; kalça, sol-sağ; çene, sol-sağ; sırt

Üst kol, sol-sağ; uyluk, sol-sağ; göğüs ve bel

Ön kol, sol-sağ; bacak, sol-sağ; karın ve boyun

2. Semptom şiddeti skalası

Yorgunluk

Sabah yorgun kalkma

Bilişsel semptomların olması

Genel somatik semptomların varlığı

çalışmalarında temel olan "neyin nasıl ölçüleceği"dir (12). OMERACT FMS atölye çalışmasında özellikle FMS'de değerlendirme ölçütlerinin standardizasyonu ve önceliği üzerinde durulmuştur $(13,14)$.

ICF, fonksiyonelliğin tanımlanması açısından OMERACT bileşenlerinin en spesifik hale getirilmesinde kullanılabilir (4).

KYA için Kısa ICF Çekirdek Dizisi daha çok FMS için yapılacak olan klinik çalışmalarda kullanım amacıyla oluşturulmuştur. KYA için Kısa ICF Çekirdek Dizisinde fonksiyonel durumu değerlendirmek için 9, etkinlikler ve katılım için 10 ve çevresel faktörler için 5 kategori olmak üzere toplam 24 kategori bulunmaktadır. Bu kategoriler ile hastaların sadece hastalığın vücut yapıları üzerindeki etkileri açısından değil, aynı zamanda etkinlikler ve katılım ile çevresel faktörler açısından da ayrıntılı değerlendirilmesi amaçlanmaktadır.

Bu çalışmanın amacı, KYA için geliştirilmiş olan ICF çekirdek dizisinin fibromiyalji hastalarındaki sağlık sorunlarının etkinlikler ve katılım ile çevresel faktörler bileşeninde değerlendirilmesidir. Çalışma, ICF'nin FMS hastalarında kullanımının değerlendirilmesi amacıyla ön çalışma olarak planlanmıştır.

\section{Metodoloji}

Çalışma prospektif, kesitsel, pilot çalışma olarak planlandı ve 2017 Haziran-2018 Mart ayları arasında yürütüldü.
Tablo 4. KYA için kullanılan ICF çekirdek dizisi (kısa)

\begin{tabular}{|c|c|c|c|}
\hline b130 & Enerji & d430 & Cisimleri kaldırma-taşıma \\
\hline b134 & Uyku & d450 & Yürüme \\
\hline b147 & Psikomotor fonksiyon & d640 & Ev işi yapma \\
\hline b152 & Emosyonel durum & d760 & Aile ilişkileri \\
\hline b1602 & Düşünce içeriği & d770 & Yakın ilişkiler \\
\hline b280 & Ağrı & d850 & İşe başlama-devam ettirme \\
\hline b455 & Egzersiz tolerans & d920 & $\begin{array}{l}\text { Boş zamanlarını } \\
\text { değerlendirme }\end{array}$ \\
\hline b730 & Kas kuvveti & e1101 & İlaç kullanımı \\
\hline b760 & İstemli hareketlerin kontrolü & e310 & Aile ilişkileri \\
\hline d175 & Problem çözme & e355 & $\begin{array}{c}\text { Sağlık profesyonellerinin } \\
\text { tutumu }\end{array}$ \\
\hline d230 & $\begin{array}{c}\text { Günlük yaşam aktivitelerini } \\
\text { yerine getirme }\end{array}$ & e410 & Yakın aile ilişkileri \\
\hline d240 & Stresle baş etme & e570 & $\begin{array}{l}\text { Sosyal sistemlerin ve } \\
\text { politikalarının }\end{array}$ \\
\hline
\end{tabular}

Çalışma için Kanuni Sultan Süleyman Eğitim ve Araştırma Hastanesi'nden etik kurul onayı alındı. Çalışmaya alınma kriterleri ACR 2016 kriterlerine göre FMS tanısı konulmuş olmak, en az 18 yaşında olmak, Türkçe bilmek, çalışmanın amacını anlamak ve onay vermek olarak belirlendi. Hastaların yaş, cinsiyet, meslek gibi sosyodemografik bilgileri kaydedildi. Çalışmaya alınma kriterlerini taşıyan 254 hastanın verisi değerlendirmeye alındı.

Çalışmada KYA için Kısa ICF Çekirdek Dizisi ICF kullanıldı. ICF Çekirdek Dizisinde yer alan 24 kategori değerlendirildi (Tablo 4).

FMS tanısı konulan hastalar tek bir araştırıcı tarafından değerlendirildi.

Çalışmanın verilerinin değerlendirilmesi için tanımlayıcı bilgiler kullanıldı, Ortalama, standart sapma, minimum, maksimum, medyan, frekans oran değerleri kullanıldı.

\section{Sonuçlar}

Hastaların demografik özellikleri incelendiğinde çalışmaya alınan hastaların \%97,6'sının kadın ( $n=248), \% 2,4$ 'ünün ise erkek $(n=6)$ olduğu görüldü. Çalışmaya dahil edilen hastaların hemen hemen hepsi İstanbul bölgesinde yaşamaktaydı. Çoğunluğu kadın olan hastaların yarısı ev hanımıydı. İş̧̧i olarak çalıştığını belirten hastalar çalışma popülasyonunun üçte birini oluştururken, hastaların \%7,1'i ise emekli idi. Hastaların sosyodemografik karakteristikleri Tablo 5'te verilmiştir. 
Tablo 5. Hastaların sosyodemografik karakteristikleri

\begin{tabular}{|c|c|c|c|c|c|c|}
\hline & & Minimum & Maksimum & Medyan & Ort. & s. $s$. \\
\hline Yaş & & 24 & 75 & 55,0 & 55,6 & 13,1 \\
\hline & & & & & $\mathrm{n}$ & $\%$ \\
\hline Cinsiyet & Kadın & & & & 248 & 97,6 \\
\hline & Erkek & & & & 6 & 2,4 \\
\hline Meslek & Ev hanımı & & & & 126 & 49,6 \\
\hline & İşçi & & & & 92 & 36,2 \\
\hline & $\begin{array}{l}\text { Serbest } \\
\text { Meslek }\end{array}$ & & & & 2 & 0,8 \\
\hline & Öğretmen & & & & 16 & 6,3 \\
\hline & Emekli & & & & 18 & 7,1 \\
\hline
\end{tabular}

Ort.: ortalama; s.s.: standart sapma
Vücut işlevlerinde yapılan değerlendirmeye göre özellikle enerji (b134), uyku (b134), psikomotor fonksiyon (b147), emosyonel durum (b152), düşünce içeriği (b1602), ağrı (b280), egzersiz tolerans (b455) ve kas kuvveti (b730) kategorilerinde orta veya ciddi düzeyde bozukluk tespit edildi (Tablo 6).

Etkinlikler ve katılım alanında yapılan değerlendirmeye göre, problem çözme (d175), günlük yaşam aktivitelerini yerine getirme (d230), stresle baş etme (d240), cisimleri kaldırma-taşıma (d430), yürüme (d450), ev işi yapma (d640), aile ilişkileri (d760), yakın ilişkiler (d770), işe başlama-devam ettirme (d850), boş zamanlarını değerlendirme (d920) kategorilerinde orta veya ciddi düzeyde sorun tespit edildi (Tablo 7).

Tablo 6. Hastaların vücut işlevlerine göre değerlendirilmeleri

\begin{tabular}{|c|c|c|c|c|c|c|c|c|}
\hline & \multicolumn{2}{|c|}{$\begin{array}{c}\text { Hafif } \\
\text { Bozukluk }\end{array}$} & \multicolumn{2}{|c|}{$\begin{array}{c}\text { Orta } \\
\text { Bozukluk }\end{array}$} & \multicolumn{2}{|c|}{$\begin{array}{c}\text { Ciddi } \\
\text { Bozukluk }\end{array}$} & \multicolumn{2}{|c|}{$\begin{array}{c}\text { Tam } \\
\text { Bozukluk }\end{array}$} \\
\hline & $n$ & $\%$ & & & $n$ & $\%$ & $n$ & $\%$ \\
\hline Enerji & 0 & 0,0 & 105 & 41,3 & 49 & 19,3 & 0 & 0,0 \\
\hline Uyku & 10 & 3,9 & 95 & 37,4 & 149 & 58,7 & 0 & 0,0 \\
\hline Psikomotor fonksiyon & 10 & 3,9 & 95 & 37,4 & 149 & 58,7 & 0 & 0,0 \\
\hline Emosyonel durum & 10 & 3,9 & 95 & 37,4 & 149 & 58,7 & 0 & 0,0 \\
\hline Düşünce & 9 & 3,5 & 96 & 37,8 & 149 & 58,7 & 0 & 0,0 \\
\hline Ağrı & 0 & 0,0 & 105 & 41,3 & 149 & 58,7 & 0 & 0,0 \\
\hline Egzersiz & 0 & 0,0 & 105 & 41,3 & 149 & 58,7 & 0 & 0,0 \\
\hline Kas Kuvveti & 0 & 0,0 & 105 & 41,3 & 149 & 58,7 & 0 & 0,0 \\
\hline İstemli Hareket & 254 & 100,0 & 0 & 0,0 & 0 & 0,0 & 0 & 0,0 \\
\hline
\end{tabular}

Tablo 7. Hastaların etkinlikler ve kalıtım ile ilgili değerlendirmeleri

\begin{tabular}{|c|c|c|c|c|c|c|c|c|}
\hline & \multicolumn{2}{|c|}{$\begin{array}{c}\text { Hafif } \\
\text { Bozukluk }\end{array}$} & \multicolumn{2}{|c|}{$\begin{array}{c}\text { Orta } \\
\text { Bozukluk }\end{array}$} & \multicolumn{2}{|c|}{$\begin{array}{c}\text { Ciddi } \\
\text { Bozukluk }\end{array}$} & \multicolumn{2}{|c|}{$\begin{array}{c}\text { Tam } \\
\text { Bozukluk }\end{array}$} \\
\hline & $n$ & $\%$ & $n$ & $\%$ & $n$ & $\%$ & $n$ & $\%$ \\
\hline Problem Çözme & 0 & 0,0 & 109 & 42,9 & 45 & 17,7 & 0 & 0,0 \\
\hline Günlük Yaşamsal Aktivite & 0 & 0,0 & 109 & 42,9 & 45 & 17,7 & 0 & 0,0 \\
\hline Stres & 0 & 0,0 & 105 & 41,3 & 49 & 19,3 & 0 & 0,0 \\
\hline Taşıma & 0 & 0,0 & 105 & 41,3 & 49 & 19,3 & 0 & 0,0 \\
\hline Yürüme & 0 & 0,0 & 105 & 41,3 & 49 & 19,3 & 0 & 0,0 \\
\hline Ev İşi Yapma & 0 & 0,0 & 105 & 41,3 & 49 & 19,3 & 0 & 0,0 \\
\hline Aile İlişki & 246 & 96,9 & 8 & 3,1 & 0 & 0,0 & 0 & 0,0 \\
\hline Yakın İlişki & 66 & 26,0 & 138 & 54,3 & 50 & 19,7 & 0 & 0,0 \\
\hline İşe başlama-devam & 66 & 26,0 & 138 & 54,3 & 50 & 19,7 & 0 & 0,0 \\
\hline Boş Zaman & 66 & 26,0 & 138 & 54,3 & 50 & 19,7 & 0 & 0,0 \\
\hline
\end{tabular}


Tablo 8. Hastaların çevresel faktörler ile ilgili değerlendirmeleri

\begin{tabular}{|c|c|c|c|c|c|c|c|c|c|c|}
\hline & & & \multicolumn{8}{|c|}{ Kolaylaştırıcı } \\
\hline & \multicolumn{2}{|c|}{ Engelleyici } & \multicolumn{2}{|c|}{$\begin{array}{c}\text { Hafif } \\
\text { Kolaylaştırıcı }\end{array}$} & \multicolumn{2}{|c|}{$\begin{array}{c}\text { Orta } \\
\text { Kolaylaştırıcı }\end{array}$} & \multicolumn{2}{|c|}{$\begin{array}{c}\text { Ciddi } \\
\text { Kolaylaştırıcı }\end{array}$} & \multicolumn{2}{|c|}{ Tam Kolaylaştırıcı } \\
\hline & $n$ & $\%$ & $n$ & $\%$ & $n$ & $\%$ & $n$ & $\%$ & $n$ & $\%$ \\
\hline Aile & 31 & 12,2 & 0 & 0,0 & 223 & 87,8 & 0 & 0,0 & 0 & 0,0 \\
\hline Sağlık Profili & 0 & 0,0 & 0 & 0,0 & 254 & 100,0 & 0 & 0,0 & 0 & 0,0 \\
\hline Aile Üye & 31 & 12,2 & 0 & 0,0 & 223 & 87,8 & 0 & 0,0 & 0 & 0,0 \\
\hline Sosyal Sistem & 0 & 0,0 & 0 & 0,0 & 254 & 100,0 & 0 & 0,0 & 0 & 0,0 \\
\hline
\end{tabular}

Çevresel faktörler alanı incelendiğinde ilaç kullanımı (e1101), aile ilişkileri (e310), sağlık profesyonellerinin tutumu (e355), yakın aile ilişkileri (e410), ve sosyal sistemlerin ve politikalarının (e570) genel olarak orta düzeyde kolaylaştırıcı olduğu tespit edilmiştir (Tablo 8).

\section{Tartışma}

Çalışmada ICF'nin sadece semptom spesifik değil aynı zamanda, etkinlikler ve katıım alanı ile çevresel faktörler alanı incelenmiş, dolayısıyla hastaların dış çevre ile olan ilişkileri veya etkileşimleri de değerlendirilmiştir.

Her hasta yaklaşık 20 dakika süresince değerlendirilmiş ve hastaların tedavi planlanması ve rehabilitasyon programlarının yapılması açısından sonuçlar hızlıca tespit edilmiştir.

Löfgren ve ark.'nın yaptığı çalışmada değerlendirme süresi 30 dakika olarak belirlenmiştir. Bu durum ICF'nin kapsamlı bir değerlendirme sistemi olması yanında değerlendirme skalasının sübjektif olması ile dolaylı ilişkili olabilir (0-4 arası değerlendirme) (15).

Bautz-Holter ve ark.'nın yaptığı bir çalışmada ise değerlendirme süresi yaklaşık 48 dakika olarak belirlenmiştir. Ancak bu çalışmada 35 kategori bulunmaktadır ve değerlendirme süresinin uzun olması da kategori sayısının fazlalığına bağlı olabilir (16).

Diğer değerlendirme ölçeklerinden farklı olarak ICF'nin kendisi bir ölçek değildir, ayrıntılı bir değerlendirme sistemidir. ICF ile yine diğer değerlendirme ölçeklerinden farklı olarak toplam skor kavramı yoktur, her problem tek başına değerlendirilir ve her bir kategorideki problemler tek tek açığa çıkmaktadır $(4,15,17)$.

Bu çalışmada vücut işlevleri alanında enerji düzeyi, uyku, emosyonel işlevler, ağrı, egzersiz toleransı ve kas kuvveti kategorilerinde problem çıkması önemlidir. Hastalardaki ağrı kategorisindeki bozukluk aynı alandaki diğer kategorileri direk veya dolaylı etkileyebilmektedir (uyku kalitesindeki bozulma, uykuya dalmada güçlük, egzersiz yapmada zorluk, vb.)

ICF Çekirdek Dizisinde yer alan yapısal faktörleri değerlendirmek için görüntüleme yöntemleri gerektirdiğinden (röntgen, MRG, vb.), yapısal faktörler çalışma kapsamına alınmamıştır. FMS'de yapısal faktörlerde bir problem tespit edilmemesi de bu faktörlerin çalışma kapsamına alınmamasının bir diğer nedenidir.

Etkinlikler ve katılım alanında ise problem çözme, günlük yaşam aktivitelerini yerine getirememe, yürüme, ev işi yapma, yakın ilişkiler (arkadaş, vb.), boş zamanlarını değerlendirme kategorilerinde orta ve ciddi düzeyde bozukluklar tespit edilmiştir. Aile ilişkilerindeki bozukluk diğer kategorilerin aksine ağırlıkı olarak hafif düzeydedir ( $n=8$, $\% 3,1)$. Bu durum toplumsal olarak kronik hastalığı olan bireyin aile tarafından dışlanmadığını gösterebilir. Nitekim çevresel faktörler alanı incelendiğinde, aile kategorisinin hastaların büyük çoğunluğu için $(n=223, \% 87,8)$ orta düzeyde kolaylaştırıcı olduğu belirlenmiştir. Hastaların ailesel ilişkilerinin bozulmaması veya az etkilenmesi, hatta ailenin hasta ve hastalık için kolaylaştırıcı özellikte olması hastalığın etkilerini azaltabilir. Hieblinger ve ark.'nın yaptığı bir çalışmada, bu yazının sonuçlarının aksine, FMS olan hastaların büyük kısmının hastalıklarından dolayı dışlandığı, kendilerini yalnız hissettikleri tespit edilmiştir (4). Bu yalnızlık ve dışlanmanın sadece arkadaş çevresinden değil, bazı doktor, sağlık profesyonelleri ve akrabalarının olumsuz tutumlarından da kaynaklanıyor olabilir. Bu çevresel tutum farklılığı farklı ülkelerde farklı kültürel özellikler ile yetişen bireylerin, aynı olaylara verdiği farklı tepkilerden kaynaklanıyor olabilir. Sonuç olarak ICF ile, sadece hastalığın semptom ve bulguları değil, ülkeler arası farklı sosyokültürel davranışlar da tespit edilebilmektedir. 
Bu çalışmanın kısıtılıkları arasında ICF sistemi ile diğer değerlendirme ölçekleri arasında karşılaştırma yapılamaması ve yapısal faktörlerin değerlendirmeye alınamaması sayılabilir. ICF ve kronik ağı ile ilgili yayınlar sınırlı sayıdadır. Rapor edilen çalışmalar ya tek bir hasta için vaka sunumu şeklindedir (18) veya çok sayıda hasta ile yapılmış çalışmalar olsa dahi sonuçları uygulanan metodun klinik çalışmalarda kullanılabilmesi için daha fazla geliştirme gerektiğini ortaya koyan çalışmalardır (16). İleride yapılacak çalışmalarda laboratuvar ve görüntüleme tekniklerinin de göz önünde bulundurulması ile ICF sisteminin hastalığın

\section{Kaynaklar}

1. Cieza A, Ewert T, Ustun TB, Chatterji S, Kostanjsek N, Stucki G. Development of ICF Core Sets for patients with chronic conditions. J Rehabil Med 2004;36:9-11. [CrossRef]

2. World Health Organization (WHO). International classification of functioning, disability, and health: ICF. Version 1.0. Geneva: World Health Organization; 2001. https://apps.who.int/iris/bitstream/ handle/10665/42407/9241545429. pdf;jsessionid=B56F33947DC15 1536AFCCA7543827ACD? sequence $=1$

3. Dernek B, Esmaeilzadeh S, Oral A. The utility of the International Classification of Functioning, Disability and Health checklist for evaluating disability in a community-dwelling geriatric population sample. Int J Rehabil Res 2015;38:144-55. [CrossRef]

4. Hieblinger R, Coenen M, Stucki G, Winkelmann A, Cieza A. Validation of the International Classification of Functioning, Disability and Health Core Set for chronic widespread pain from the perspective of fibromyalgia patients. Arthritis Res Ther 2009;11:R67. [CrossRef]

5. Guyatt GH, Feeny DH, Patrick DL. Measuring health-related quality of life. Ann Intern Med 1993;118:622-9. [CrossRef]

6. Wolfe F, Clauw DJ, Fitzcharles MA, Goldenberg DL, Hauser W, Katz RL, et al 2016 Revisions to the 2010/2011 fibromyalgia diagnostic criteria. Semin Arthritis Rheum 2016;46:319-29. [CrossRef]

7. Wolfe F, Ross K, Anderson J, Russell IJ, Hebert L. The prevalence and characteristics of fibromyalgia in the general population. Arthritis Rheum 1995;38:19-28. [CrossRef]

8. Clauw DJ, Crofford LJ. Chronic widespread pain and fibromyalgia: what we know, and what we need to know. Best Pract Res Clin Rheumatol 2003;17:685-701. [CrossRef]

9. Richardson JC, Ong BN, Sim J. Experiencing chronic widespread pain in a family context: giving and receiving practical and emotional support. Sociol Health IIIn 2007;29:347-65. [CrossRef]

10. Gupta A, Silman AJ, Ray D, Morriss R, Dickens C, MacFarlane GJ, et al. The role of psychosocial factors in predicting the onset of chronic widespread pain: results from a prospective population-based study. Rheumatology (Oxford) 2007;46:666-71. [CrossRef] geniş çaplı etkilerinin değerlendirmesi konusundaki faydası daha ayrıntılı analiz edilebilir.

FMS, sadece hasta olan bireyi değil, bireyin yaşadığı alanda bireyle etkileşim halinde olan diğer toplumsal grupları da etkileyen ve geniş çaplı sistemik etkilerin ortaya çıkmasına neden olan kronik bir hastalıktır. ICF sistemi ile FMS gibi hastalıklarda, sadece hastalığın etkileri değil, hastalığın direk veya dolaylı olarak oluşturduğu çevresel etkiler de ayrıntılı incelenebilir.

11. Sylvain H, Talbot LR. Synergy towards health: a nursing intervention model for women living with fibromyalgia, and their spouses. J Adv Nurs 2002;38:264-73. [CrossRef]

12. Stucki G, Boonen A, Tugwell P, Cieza A, Boers M. The World Health Organisation International Classification of Functioning, Disability and Health: a conceptual model and interface for the OMERACT process. J Rheumatol 2007;34:600-6.

13. Mease P. Fibromyalgia syndrome: review of clinical presentation, pathogenesis, outcome measures, and treatment. J Rheumatol Suppl 2005;75:6-21.

14. Mease P, Arnold LM, Bennett R, Boonen A, Buskila D, Carville S, et al. Fibromyalgia syndrome. J Rheumatol 2007;34:1415-25.

15. Lofgren M, Ekholm J, Broman L, Njoo P, Schult ML. Using a profile of a modified Brief ICF Core Set for chronic widespread musculoskeletal pain with qualifiers for baseline assessment in interdisciplinary pain rehabilitation. J Multidiscip Healthc 2013;6:311-21. [CrossRef]

16. Bautz-Holter E, Sveen U, Cieza A, Geyh S, Roe C. Does the International Classification of Functioning, Disability and Health (ICF) core set for low back pain cover the patients' problems? A crosssectional content-validity study with a Norwegian population. Eur J Phys Rehabil Med 2008;44:387-97. https://www.minervamedica.it/ en/getfreepdf/xUJXGmDZrMxupGFw5\%252FV1ImYVHCdlrsR8HNQ AbCFGf39ljlxeChCcOb\%252Bq84iN8APBIVHcXXDuP9ySxiYJhgj2BQ \%253D\%253D/R33Y2008N04A0387.pdf

17. Amris K, Waehrens EE, Stockmarr A, Bliddal H, Danneskiold-Samsoe B. Factors influencing observed and self-reported functional ability in women with chronic widespread pain: a cross-sectional study. J Rehabil Med 2014;46:1014-21. [CrossRef]

18. Finger ME, Selb M, De Bie R, Escorpizo R. Using the International Classification of Functioning, Disability and Health in Physiotherapy in Multidisciplinary Vocational Rehabilitation: A Case Study of Low Back Pain. Physiother Res Int 2015;20:231-41. [CrossRef] 